\title{
Hyphenated 3D-QSAR statistical model-drug repurposing analysis for the identification of potent neuraminidase inhibitor
}

\author{
K. Rohini ${ }^{1} \cdot$ V. Shanthi ${ }^{1}{ }^{1}$
}

Received: 9 August 2017 / Accepted: 10 April 2018 / Published online: 23 April 2018

(c) Springer Science+Business Media, LLC, part of Springer Nature 2018

\begin{abstract}
The Influenza A virus is one of the principle causes of respiratory illness in human. The surface glycoprotein of the influenza virus, neuraminidase (NA), has a vital role in the release of new viral particle and spreads infection in the respiratory tract. It has been long recognized as a valid drug target for influenza A virus infection. Oseltamivir is used as a standard drug of choice for the treatment of influenza. However, the emergence of mutants with novel mutations has increased the resistance to potent NA inhibitor. In the present investigation, we have employed computer-assisted combinatorial techniques in the screening of 8621 molecules from Drug Bank to find potent NA inhibitors. A three-dimensional pharmacophore model was generated from the previously reported 28 carbocylic influenza NA inhibitors along with oseltamivir using PHASE module of Schrödinger Suite. The model generated consists of one hydrogen bond acceptor (A), one hydrogen bond donors (D), one hydrophobic group $(\mathrm{H})$, and one positively charged group $(\mathrm{P})$, ADHP. The hypothesis was further validated for its integrity and significance using enrichment analysis. Subsequently, an atom-based 3D-QSAR model was built using the common pharmacophore hypothesis (CPH). The developed 3D-QSAR model was found to be statistically significant with $R^{2}$ value of 0.9866 and $Q^{2}$ value of 0.7629 . Further screening was accomplished using three-stage docking process using the Glide algorithm. The resultant lead molecules were examined for its drug-like properties using the Qikprop algorithm. Finally, the calculated $\mathrm{pIC}_{50}$ values of the lead compounds were validated by the AutoQSAR algorithm. Overall, the results from our analysis highlights that lisinopril (DB00722) is predicted to bind better with NA than currently approved drug. In addition, it has the best match in binding geometry conformations with the existing NA inhibitor. Note that the antiviral activity of lisinopril is reported in the literature. However, our paper is the first report on lisinopril activity against influenza A virus infection. These results are envisioned to help design the novel NA inhibitors with an increased antiviral efficacy.
\end{abstract}

Keywords Neuraminidase $\cdot$ Pharmacophore Hypothesis $\cdot$ Enrichment Analysis $\cdot 3 D-Q S A R$ Model $\cdot$ AutoQSAR $\cdot$ Qikprop

\section{Introduction}

In the recent years, the Influenza A virus infection has become a serious threat for human health worldwide. This virus is a negative sense, single stranded, and segmented RNA viruses, which belongs to the orthomyxoviridae family [1]. The two major surface glycoproteins of influenza viruses, hemaglutinin (HA) and neuraminidase (NA), have crucial roles in the life cycle of the viruses. There are different

V. Shanthi

shanthi.v@vit.ac.in

1 Department of Biotechnology, School of BioSciences and Technology, Vellore Institute of Technology, Vellore, Tamil Nadu 632014, India subtypes of each protein, HA having 16 subtypes $(\mathrm{H} 1, \mathrm{H} 2$, $\mathrm{H} 3, \ldots, \mathrm{H} 16)$ and NA having 9 subtypes $(\mathrm{N} 1, \mathrm{~N} 2, \ldots, \mathrm{N} 9)$ [2]. The glycoproteins HA and NA together are believed to interact with the surface receptors of the host cell, assisting the viral infection [3]. The infection cycle of influenza virus involves several steps. Initially, the influenza virus binds to sialic acid- $\alpha$ 2, 6-galactose, which is present on the cell surface [4]. Subsequently, the uncoating of nucleocapsid and propagation of genetic material takes place and finally ends up with the expression and release of viral protein [5]. The virus entry is mediated by HA antigen upon binding to the sialic acid receptor. A specific linkage of sialic acid receptor is broken by NA, which leads to the release of newly produced virions from the infected cells. Therefore, NA has been considered as the most significant target for preventing the propagation of influenza virus in the host [1]. To prevent mortality and morbidity rate related to it, FDA-approved NA 
inhibitors, oseltamivir (Tamiflu) and zanamivir (Relenza), has been widely used for influenza treatment [6]. In addition both these drugs have prolonged duration of antiviral activity. However, they entirely differ in the mode of deliverance, pharmacological action, and side effects. Oseltamivir when compared with zanamivir has good oral availability [7]. Hence, it is the most preferred antiviral drug for treating and preventing influenza virus infection. As a consequence of its highly polar nature, zanamivir has poor oral availability and is thus administered through inhalation. This eventually limits its usage in treating the elderly patients as it may induce bronchospasm [6]. In the year 2010, two new NA inhibitors, laninamivir and peramivir, were approved for treating influenza virus infection [8].

Despite the number of available drugs for NA inhibition, drug resistance is the major setback in the influenza therapeutics. The drug resistance offered by the virus a repercussion of mutations, which occur due to substitutions in the amino acid residues. These substitutions are caused by the continuous antigenic drift and erratic antigenic shift in the surface glycoproteins. However, this might have also emerged due to extensive use of NA inhibitors [9]. In 2007 to 2008 , the histidine residue present at position 274 of influenza A virus was found to be substituted by tyrosine which offered resistance to oseltamivir [10]. In recent times, the prominence of R292K mutation in the novel H7N9 avian influenza virus was accounted to be related with reduced clinical result [11]. In another study, N294S mutation has been found to confer decreased sensitivity especially to oseltamivir and has been noticed in both N1 and N2 subtype of influenza A virus [12]. One more instance of mutation wherein, substitution of glutamate residue at $119^{\text {th }}$ position by glycine is developed under zanamivir selective pressure [7]. Additionally, the I221L variant of NA provides lower affinity for oseltamivir and zanamivir [13]. Advent of other cases of affiliated mutation such as, I223R and H275Y under oseltamivir treatment highlights the importance of close examination of patients under treatment [14].

An amalgamation of both conventional drug discovery process and computational strategies would lead to remarkable development in drug discovery [15]. Virtual screening is known as the most dynamic and advantageous technology in revelation of novel drug-like compounds [1619]. Most importantly, pharmacophore-based virtual screening and 3D-QSAR modeling has shown great promise in sorting large libraries of bioactive molecules and analyzing the biological activity of ligands. For instance, a combination of pharmacophore modeling and 3D-QSAR studies has been carried out to identify novel c-KIT inhibitors in treating small cell lung cancer [20]. Another instance, wherein consolidation of these two strategies were employed to identify anti-ataxia compounds for treating a rare neurological disorder termed as Spinocerebellar ataxia (SCA-2) type-2 [21]. Hence, we have employed hyphenated 3DQSAR [22] statistical model-drug repurposing analysis to screen potentially potent and selective NA inhibitor. Indeed, the results of our analysis are of immense importance for virologist to design better and safer drugs in the near future.

\section{Materials and Methods}

\section{Dataset Preparation}

Twenty-eight carbocylic influenza NA inhibitors with the corresponding $\mathrm{IC}_{50}$ data were retrieved from the available literature [23] along with oseltamivir for the 3D-QSAR studies. It includes 11 carbocylic analogs with linear alkyl chains, 10 branched alkyl chains and 7 aryl and aryl alkyl side chains. The inhibition concentrations $\left(\mathrm{IC}_{50}\right)$ were converted into negative logarithmic values to obtain $\mathrm{pIC}_{50}$ values that aids in linearization of the QSAR equation [24]. The dataset was classified into actives, inactives, and intermediates based on the pIC50 value to find common pharmacophore hypothesis (CPH). For instance, the compounds with $\mathrm{pIC}_{50}$ value $>8.00$ were considered to be active, those with $\mathrm{pIC}_{50}$ value $<5.00$ were considered to be inactive. Compounds having $\mathrm{pIC}_{50}$ value between 5.00 and 8.00 were considered as intermediates. The details are shown in Table 1. The X-ray crystal structure of native NA and mutants (H274Y, R292K, E119G, N294S, D179E, I223R, and I221L) used in our study was retrieved from the Protein Data Bank (PDB) [25]. The corresponding PDB code for native NA is 3 TI6 with a resolution of $1.69 \AA$ [26] and for mutants is $4 \mathrm{HZZ}, 1 \mathrm{~L} 7 \mathrm{H}, 1 \mathrm{~L} 7 \mathrm{G}, 3 \mathrm{CL} 2,3 \mathrm{~K} 39$, $4 \mathrm{~B} 7 \mathrm{~N}$, and 4CPM, respectively. For the virtual screening study, a total of 8621 molecules were considered from Drug bank. The set consist of 2037 FDA-approved drugs. The number of experimental and investigational drugs includes 4953 and 1991, respectively.

\section{Protein Preparation}

The protein preparation wizard of Schrödinger Suite was employed to prepare the 3D structure of NA protein retrieved from PDB. It helps in the structural correction of defects, which may be pre-existing in the molecules. Subsequently, the protein was pre-processed and water molecules were eliminated up to a distance of $5.0 \AA$. Heteroatoms that do not affect the protein structure, conformation or function were omitted; right bond orders were allocated and hydrogen atoms were added to the carbon atoms. The structure was then optimized and minimized using Optimized Potentials for Liquid Simulations (OPLS)2005 force field. Finally, geometry refinement was performed with restrained minimization such that the junction 
Table 1 Structures and biological activities of carbocylic NA inhibitors used for 3D-QSAR analysis

\section{Compound Structure of the compound}

Linear alkyl chains

1<smiles>CC(=O)N[C@H]1[C@@H](N)CC(C(=O)O)=C[C@H]1O</smiles>

2<smiles>C=C(C)N[C@H]1[C@H](N)CC(C(=O)O)=C[C@H]1OC</smiles>

3<smiles>CCO[C@H]1C=C(C(=O)O)C[C@H](N)[C@H]1NC(C)=O</smiles>

4<smiles>CCCO[C@H]1C=C(C(=O)O)C[C@H](N)[C@H]1NC(C)=O</smiles>

5<smiles>CCCCO[C@H]1C=C(C(=O)O)C[C@H](N)[C@H]1NC(C)=O</smiles>

6<smiles>CCCCCO[C@H]1C=C(C(=O)O)C[C@H](N)[C@H]1NC(C)=O</smiles>

NA inhibition $\mathrm{IC}_{50}(\mathrm{nM}) \quad$ Observed $\mathrm{pIC}_{50}$

QSAR set Pharm set

6300

5.201

Training Inactive

3700

5.432

Training

Inactive

2000

5.699

Training Inactive

180

6.745

Test

Intermediate

300

6.523

Training Intermediate

200

6.699

Training

Intermediate 
Table 1 (continued)

Compound Structure of the compound

7<smiles>CCCCCCO[C@H]1C=C(C(=O)O)C[C@H](N)[C@H]1NC(C)=O</smiles>

8<smiles>CCCCCCCO[C@H]1C=C(C(=O)O)C[C@H](N)[C@H]1NC(C)=O</smiles>

9<smiles>CCCCCCCCO[C@H]1C=C(C(=O)O)C[C@H](N)[C@H]1NC(C)=O</smiles>

10<smiles>CCCCCCCCCO[C@H]1C=C(C(=O)O)C[C@H](N)[C@H]1NC(C)=O</smiles>

11<smiles>CCCCCCCCCCO[C@H]1C=C(C(=O)O)C[C@H](N)[C@H]1NC(C)=O</smiles>

Branched akyl chains

12<smiles>CC(=O)N[C@@H]1[C@@H](N)CC(C(=O)O)=C[C@H]1OCC(C)C</smiles>

NA inhibition $\mathrm{IC}_{50}(\mathrm{nM}) \quad$ Observed $\mathrm{pIC}_{50} \quad$ QSAR set $\quad$ Pharm set

150

6.824

Test

Intermediate

270

6.569

Training Intermediate

6.745

Training

Intermediate

210

6.678

Test

Intermediate

600

6.222

Test

Intermediate

$6.699 \quad$ Training Intermediate 
Table 1 (continued)

Compound Structure of the compound

13<smiles>CC[C@H](C)O[C@H]1C=C(C(=O)O)C[C@H](N)[C@H]1NC(C)=O</smiles>

14<smiles>CC[C@H](C)O[C@H]1C=C(C(=O)O)C[C@H](N)[C@H]1NC(C)=O</smiles>

15<smiles>CCC(CC)O[C@@H]1C=C(C(=O)O)C[C@H](N)[C@H]1NC(C)=O</smiles>

16<smiles>C=CC[C@H](CC)O[C@@H]1C=C(C(=O)O)C[C@H](N)[C@H]1NC(C)=O</smiles>

17<smiles>C=CC[C@H](CC)O[C@@H]1C=C(C(=O)O)C[C@H](N)[C@H]1NC(C)=O</smiles>

NA inhibition $\mathrm{IC}_{50}(\mathrm{nM}) \quad$ Observed $\mathrm{pIC}_{50} \quad$ QSAR set Pharm set

10

8.000

Training

Active

9

8.046

Training

Active

1

9.000

Test

Active

1

9.000

Training

Active

3

8.523

Training

Active 
Table 1 (continued)

Compound Structure of the compound

18<smiles>CCCCCCC[C@H](CC)O[C@H]1C=C(C(=O)O)C[C@H](N)[C@H]1NC(C)=O</smiles>

19<smiles>CC(=O)N[C@H]1[C@H](N)CC(C(=O)O)=C[C@H]1OC1CCCCC1</smiles>

20<smiles>CC[C@H](CC1CCCCC1)O[C@H]1C=C(C(=O)O)C[C@H](N)[C@H]1NC(C)=O</smiles>

21<smiles>CC[C@H](CCC1CCCCC1)O[C@@H]1C=C(C(=O)O)C[C@H](N)[C@H]1NC(C)=O</smiles>

Aryl and aryl alkyl side chain

22<smiles>CC(=O)N[C@H]1[C@H](N)CC(C(=O)O)=C[C@H]1Oc1ccccc1</smiles>

NA inhibition $\mathrm{IC}_{50}(\mathrm{nM}) \quad$ Observed $\mathrm{pIC}_{50} \quad$ QSAR set $\quad$ Pharm set

9.000

Training

Active

60

7.222

Training Intermediate

16

7.796

Test

Intermediate

1

9.000

Training

Active

6.276

Test

Intermediate 
Table 1 (continued)

Compound Structure of the compound

23<smiles>CC(=O)N[C@H]1[C@@H](N)CC(C(=O)O)=C[C@H]1OCc1ccccc1</smiles>

24<smiles>CC[C@H](CCc1ccccc1)O[C@@H]1C=C(C(=O)O)C[C@H](N)[C@H]1NC(C)=O</smiles>

25<smiles>CC[C@H](CCc1ccccc1)O[C@@H]1C=C(C(=O)O)C[C@H](N)[C@H]1NC(C)=O</smiles>

26<smiles>CC(=O)N[C@H]1C(N)CC(C(=O)O)=C[C@H]1OC(Cc1ccccc1)Cc1ccccc1</smiles>

NA inhibition $\mathrm{IC}_{50}(\mathrm{nM}) \quad$ Observed $\mathrm{pIC}_{50} \quad$ QSAR set $\quad$ Pharm set

620

6.208

Test

Intermediate

0.3

$>1000$
9.523

7.921

6.000
Training Active

Test Intermediate
12

. 
Table 1 (continued)

\begin{tabular}{llllll}
\hline Compound & Structure of the compound & NA inhibition $\mathrm{IC}_{50}(\mathrm{nM})$ & Observed pIC & QSAR set & Pharm set \\
\hline $\mathbf{2 7}$ & $>1000$ & 6.000 & Training & Inactive
\end{tabular}<smiles>CC(=O)NC1C(N)CC(C(=O)O)=CC1OC(CCCc1ccccc1)CCCc1ccccc1</smiles>

28<smiles>CC(=O)N[C@H]1[C@H](N)CC(C(=O)O)=C[C@H]1OCCCc1ccc(-c2ccccc2)cc1</smiles>

Oseltamivir carboxylate

29<smiles>CCC(CC)O[C@@H]1C=C(C(=O)O)C[C@H](N)[C@H]1NC(C)=O</smiles>

90

7.046

Test

Intermediate of atoms had a default value of root mean square deviation (RMSD) of $0.3 \AA$ [27].

\section{Ligand Preparation}

The 29 molecules were processed using "Pharmacophore Alignment and Scoring Engine (PHASE)" module that possesses in-built LigPrep software. The ligands were prepared to refine them before the development of pharmacophore and 3D-QSAR model. The refining step includes hydrogen attachment, 2D to 3D structure conversion, stereoisomer generation, and identifying the most probable ionization states [28, 29]. Subsequently, the ConfGen tool was utilized to generate conformers for the ligands. Of note, Macromodel torsion angle search approach followed by minimization using OPLS-2005 force field was utilized to generate the ligand conformers [30]. This process was then followed by the pharmacophore and 3D-QSAR model generation.

\section{Pharmacophore Model Generation}

The PHASE module of Schrödinger Suite was used to generate pharmacophore and an atom-based 3D-QSAR model. PHASE module could either generate pharmacophore-based or atom-based QSAR model. As the dataset comprises congeneric set of molecules, an effort was made to generate atom-based QSAR model. Prior to the model generation, the ligands present in the dataset were divided into training set and test set in such a way that $70 \%$ of the molecules were in training set and the rest $30 \%$ in test set. The training set is used to generate the QSAR model and the test set on the other hand is used for the validation of generated model [31]. 
Subsequently, using these 29 ligands a pharmacophore model was generated. The six dominating pharmacophoric features defined by a set of SMARTS patterns (Smiles ARbitary Target Specification patterns), namely hydrogen bond acceptor (A), hydrogen bond donor (D), hydrophobic group $(\mathrm{H})$, aromatic ring $(\mathrm{R})$, negatively ionizable $(\mathrm{N})$, and positively ionizable $(\mathrm{P})$ were considered [32-34]. All the $\mathrm{CPH}$ were then scrutinized using scoring function to select a proper hypothesis for 3D-QSAR model generation. Apart from the survival active and survival inactive scores, a rescoring was also executed to refine the hypothesis.

\section{Enrichment Analysis and 3D-QSAR Modeling}

Prior to 3D-QSAR model generation, the generated pharmacophore model performance to select active ligands from a large decoy set was examined using "Enrichment calculator" tool of Schrödinger Suite [24]. The decoy set of molecules for NA protein was downloaded from Directory of useful decoys (DUD) database [35]. A total of 1883 compounds, comprising 1874 decoys and 9 known inhibitors was used to evaluate the goodness of the model. Consequently, the ability of the pharmacophore model to recover known actives was examined using the parameters such as enrichment factor (EF) and receiver operating characteristic curve value (ROC) [36]. Finally, QSAR model built with a grid spacing size of $1 \AA$ and partial least square (PLS) factor of 3 . The PLS factor was calculated using the rule of $N / 5$, where $N$ stands for total number of training set molecules [32].

\section{High-Throughput Virtual Screening and Molecular Docking}

Molecular docking is a widely used technique to generate and score putative protein-ligand complexes based on their calculated binding affinities. This process has been successfully used for discovering potent ligands by filtering out compounds that do not bind efficiently to the binding site residues $[37,38]$. In the present study, Glide module of Schrödinger Suite was used to perform molecular docking process for the identification of "hit" molecules obtained from the pharmacophore-based screening. The prepared NA protein (PDB ID: 3TI6) structure was used as receptor. The receptor grid was generated for the refined protein using information about the active-site residues obtained from the sitemap analysis [1, 39]. Finally, the ligands were docked against the generated grid in a step-wise process, using the Glide high-throughput virtual screening (HTVS), standard precision (SP), and extra precision (XP) mode. This stepwise process of docking searches for favorable interactions between ligand molecules and protein. Consequently, the best molecules were selected based on the glide score obtained in the docking analysis [40]. The effectiveness of the hit molecule was further examined against the NAmutant structures (PDB ID: 4HZZ, 1L7H, 1L7G, 3CL2, $3 \mathrm{~K} 39,4 \mathrm{~B} 7 \mathrm{~N}$, and 4CPM). In addition, the resultant hits and their corresponding predicted pIC50 data were utilized to examine the 3D-QSAR model by employing AutoQSAR algorithm.

\section{Results and Discussion}

\section{Development of Pharmacophore Hypothesis}

The PHASE module of the Schrödinger Suite that works on tree-based partitioning algorithm was used for generating pharmacophore and 3D-QSAR model. It thoroughly analyses the spatial arrangement of chemical features that are necessary for the biological activity of the ligands. The ligands were initially prepared and then utilized for identifying $\mathrm{CPH}$. Moreover, the ligands were divided into actives and inactives based on the $\mathrm{pIC}_{50}$ value. The molecule with $\mathrm{pIC}_{50}$ value 8 or greater than 8 were considered as actives, and the molecules with $\mathrm{pIC}_{50}$ value 5 or below were considered as inactives. Compounds with $\mathrm{pIC}_{50}$ value lying in between the threshold value range were considered as intermediate compounds. Additionally, scoring procedure was performed that provided an insight into the quality of alignment of active and inactive molecules by measuring a survival score $(S)$, given as:

$$
S=W_{\text {site }} S_{\text {site }}+W_{\text {vec }} S_{\text {vec }}+W_{\text {vol }} S_{\text {vol }}+W_{\text {sel }} S_{\text {sel }}+W_{\text {rew }}^{m},
$$

where, $\mathrm{S}$ and $\mathrm{W}$, stands for the scores and weights respectively; $S_{\text {site }}$ is the alignment score, which is the RMSD in the site position; $S_{\text {vec }}$ represents vector score, which is the average value of cosine of angle between the vector features in the aligned structure; $S_{\text {vol }}$ is the volume score obtained from the overlapping of Van der Waals models of non-hydrogen atoms of each structure; $S_{\text {sel }}$ is the selectivity score, which represents the part of molecule matching the hypothesis irrespective of its activity against receptor; weights $W_{\text {site }}, W_{\text {vec }}, W_{\text {vol }}$, and $W_{\text {rew }}$ are user modifiable with a default value of 1.0 while the default value for $W_{\text {sel }}$ is 0.0 . $W_{\text {rew }}^{m}$ stands for reward weight given by $m-1$, where $m$ represents the number of active molecule which matches the hypothesis [41, 42].

Subsequently, the top four pharmacophore models were generated, which gratified internal parameters such as vector, volume, and survival activity. Finally, a four feature pharmacophore model was selected for NA inhibitors with highest survival inactive score of 3.241. The best pharmacophore model, ADHP, consisted of one hydrogen bond acceptor (A), one hydrogen bond donor (D), one 
hydrophobic group $(\mathrm{H})$, and one positively charged group (P) (Fig. 1). Consequently, this hypothesis was used for further analysis.

\section{Enrichment Analysis}

The discriminating power of the generated pharmacophore model was performed using enrichment calculator tool of Schrödinger Suite. The EF (1\%) value of 99 was obtained for the generated model. This result clearly signifies the highest recovery rate of true positive from the decoy set. Further, ROC parameter was also calculated. ROC highlights the relationship between the sensitivity (true positive) and specificity (false positive) of a test. The ROC plot for our set is shown in Fig. 2. The ROC value of 1 indicates that pharmacophore has a probability of screening the compounds $100 \%$ effectively from Decoy set. It is also clear from the figure that ROC curve is initially a vertical line implying that the model is able to efficiently find and rank the actives at the beginning of the screening process [36]. Overall, the enrichment analysis suggests that the generated pharmacophore model is ideal for both 3D-QSAR model generation and virtual screening analysis.

\section{Building 3D-QSAR Model}

The ADHP hypothesis was further validated by predicting QSAR model and was analyzed with the help of PLS analysis by aligning the training set molecules on this pharmacophore. The hypothesis was then employed to generate the 3D-QSAR model. As higher values of PLS factor may cause over-fitting of statistical model, a value of 3 was chosen for the PLS analysis with grid spacing of $1 \AA$ [43]. The CPH was evaluated by different statistical

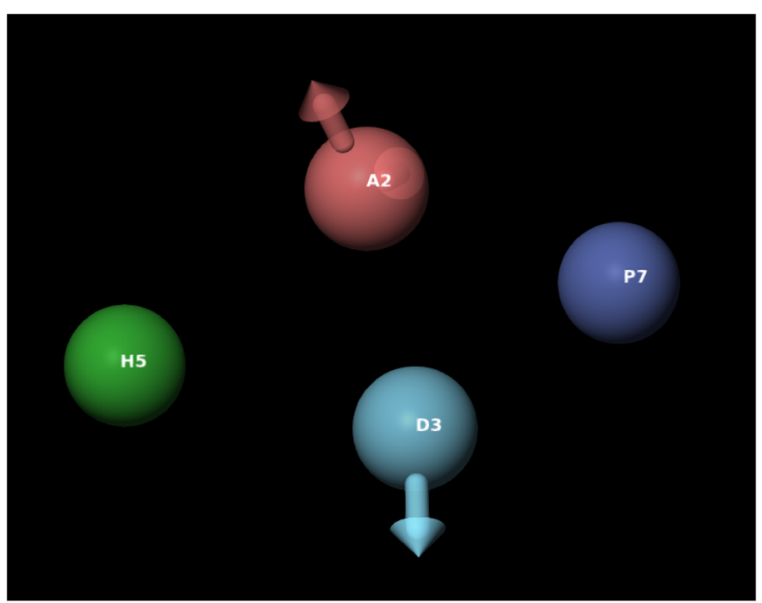

Fig. 1 Pharmacophore model (ADHP) generated from PHASE module illustrating one hydrogen bond acceptor (A2; red), one hydrogen bond donor (D3; light blue), one hydrophobic group (H5; green), and one positively charged group (P7; dark blue) (color figure online)

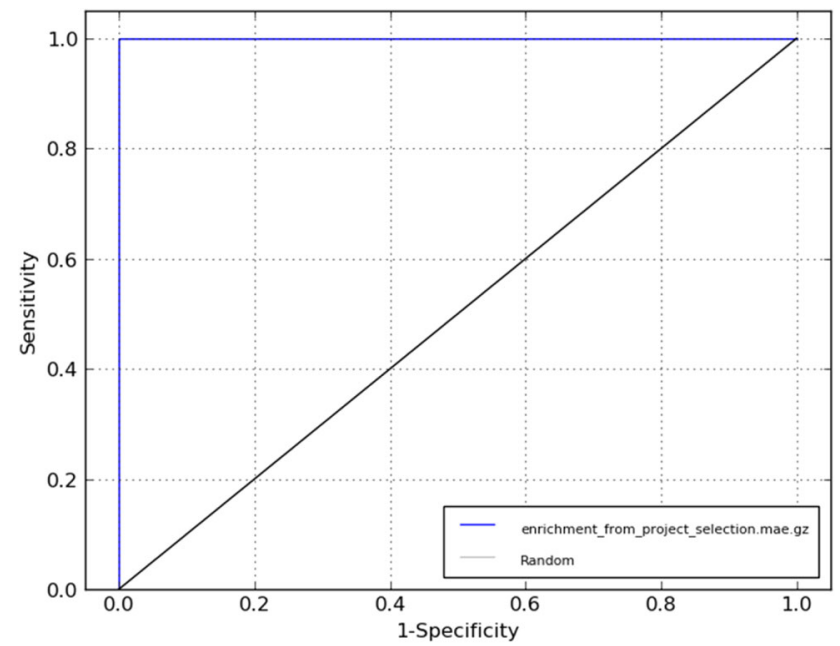

Fig. 2 ROC curve of a generated pharmacophore model (ADHP)

parameters such as correlation coefficient $\left(R^{2}\right)$, squared value for the predicted activities $\left(Q^{2}\right)$, standard deviation (SD), root-mean square error (RMSE), correlation between the predicted and observed activities for the test set (Pearson- $R$ ), and variance ratio $(F)$ (Table 2). For instance, the analysis yielded a very high $F$ value of 342.4 along with a small Pearson- $R$ value of 0.9016 , which signifies the model as statistically superior. Moreover, $R^{2}$ and $Q^{2}$ value of 0.9866 and 0.7629 , respectively, substantiate with the condition for a QSAR model to be highly predictive. Interestingly, a smaller SD value and RMSE value of 0.1754 and 0.4818 , respectively, imply that the model used for generating the 3D-QSAR model is the best. Furthermore, the predicted and experimental pIC50 values of training set and test set molecules were also compared. It is clear from the Table 3 that predicted $\mathrm{pIC}_{50}$ values and the experimental $\mathrm{pIC}_{50}$ values were quite similar with high fitness score, which indicates the scrupulousness of predicted model. In addition, a graph was plotted that depicted the experimental versus predicted $\mathrm{pIC}_{50}$ values of both training and test set molecules of the model. The graph along with equation and $R^{2}$ value is shown in Fig. 3. It illustrates that all the values are plotted around the best fit line, which indicates the significance of the model.

\section{Analysis of Contour Map}

The PHASE module has the ability to generate contour maps consisting of favorable (blue cubes) and unfavorable (red cubes) regions. Moreover, these maps have a significant role in determining the positions of substitutions for the enhancement of biological activity of a ligand. However, an insight into the inhibitory activity can be achieved by analyzing the map against most inactive (compound 1) and most active (compound 24) compounds. Hence, the 
Table 2 Statistics of atom-based 3D-QSAR results for the CPH

\begin{tabular}{ll}
\hline Parameters & Values \\
\hline PLS factor & 3 \\
SD & 0.1754 \\
$R^{2}$ & 0.9866 \\
$F$ & 342.4 \\
Stability $^{\mathrm{a}}$ & 0.5554 \\
RMSE $^{2}$ & 0.4818 \\
$Q^{2}$ & 0.7629 \\
Pearson- $R$ & 0.9016
\end{tabular}

PLS factor partial least square factor, $S D$ standard deviation of regression, $R^{2}$ correlation coefficient, $F$ variance ratio, $R M S E$ rootmean-square error, $Q^{2}$ squared value for the predicted activities, Pearson- $R$ correlation between the predicted and observed activities for the test set

astability of the model

Table 3 Experimental $\mathrm{pIC}_{50}$ value, predicted $\mathrm{pIC}_{50}$ value, and fitness score of compounds

\begin{tabular}{|c|c|c|c|}
\hline Compound & $\begin{array}{l}\text { Experimental activity } \\
\left(\mathrm{pIC}_{50}\right)\end{array}$ & $\begin{array}{l}\text { Predicted activity } \\
\left(\mathrm{pIC}_{50}\right)\end{array}$ & $\begin{array}{l}\text { Fitness } \\
\text { score }\end{array}$ \\
\hline 1 & 5.201 & 5.16 & 2.27 \\
\hline 2 & 5.432 & 5.47 & 1.27 \\
\hline 3 & 5.699 & 5.49 & 2.15 \\
\hline 4 & 6.745 & 6.42 & 2.14 \\
\hline 5 & 6.523 & 6.70 & 2.31 \\
\hline 6 & 6.699 & 6.70 & 2.31 \\
\hline 7 & 6.824 & 7.20 & 2.40 \\
\hline 8 & 6.569 & 6.85 & 2.55 \\
\hline 9 & 6.745 & 6.65 & 2.22 \\
\hline 10 & 6.678 & 6.65 & 2.19 \\
\hline 11 & 6.222 & 6.75 & 2.06 \\
\hline 12 & 6.699 & 6.64 & 2.30 \\
\hline 13 & 8.000 & 7.92 & 2.35 \\
\hline 14 & 8.046 & 7.92 & 2.35 \\
\hline 15 & 9.000 & 8.56 & 3.00 \\
\hline 16 & 9.000 & 8.89 & 2.72 \\
\hline 17 & 8.523 & 8.46 & 2.96 \\
\hline 18 & 9.000 & 8.90 & 2.63 \\
\hline 19 & 7.222 & 6.98 & 2.00 \\
\hline 20 & 7.796 & 7.90 & 1.97 \\
\hline 21 & 9.000 & 9.03 & 2.52 \\
\hline 22 & 6.276 & 6.71 & 2.02 \\
\hline 23 & 6.208 & 6.77 & 2.02 \\
\hline 24 & 9.523 & 9.73 & 3.00 \\
\hline 25 & 7.91 & 8.32 & 2.72 \\
\hline 26 & 6.000 & 6.33 & 2.10 \\
\hline 27 & 6.000 & 6.04 & 2.29 \\
\hline 28 & 7.046 & 7.94 & 2.19 \\
\hline 29 & 9.000 & 8.52 & 3.00 \\
\hline
\end{tabular}

(a)

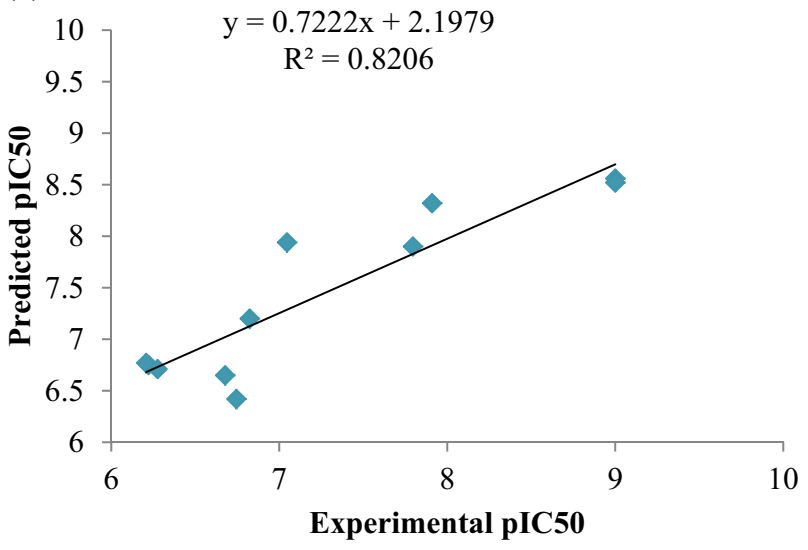

(b)

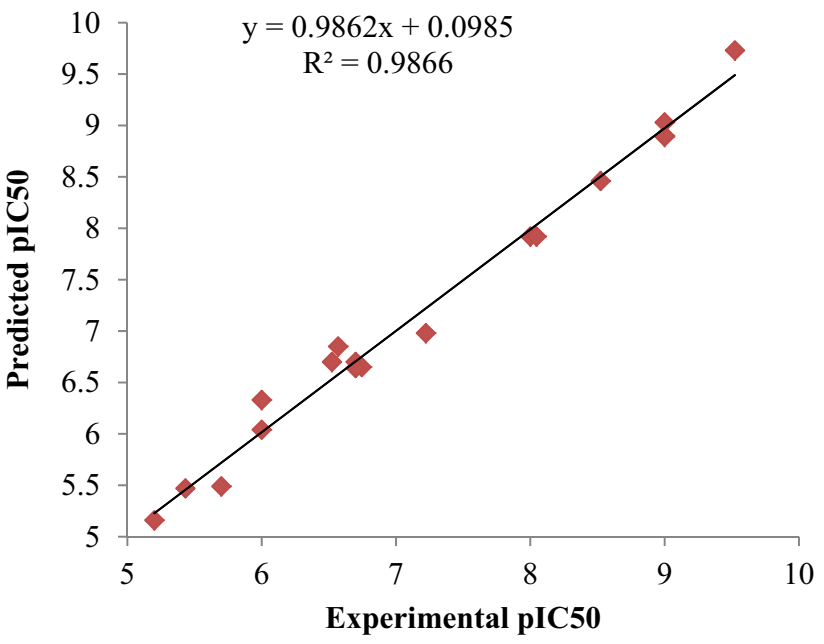

Fig. 3 Relation between predicted pIC50 and experimental pIC50 values of $\mathbf{a}$ test set and $\mathbf{b}$ training set of molecules

contour maps were created for most active and inactive compounds. In our study, the effect of hydrogen bond donor on both ligands (Fig. 4), its hydrophobic effect (Fig. 5) and its electron-withdrawing nature (Fig. 6) were visualized.

The hydrogen bond donor mapping explains the presence of favorable regions near amine group $\left(-\mathrm{NH}_{2}\right)$, which is the positively charged feature and the hydrogen bond donor group at $\mathrm{C} 6$ and $\mathrm{C} 7$ position of both the ligands. In addition, the presence of favorable region near hydrogen atom of carboxyl group in active compound specifies its significance for activity when compared to that of inactive compound (Fig. 4a). Moreover, the presence of unfavorable region near hydroxide group of inactive compound might cause decrease in its activity (Fig. 4b).

The hydrophobic effect of active and inactive ligands reveals that presence of more favorable regions in active ligand (Fig. 5a) could increase its activity when compared with inactive compound. It is clear from the figure that the inactive compound lacks a hydrophobic feature (Fig. 5b), 


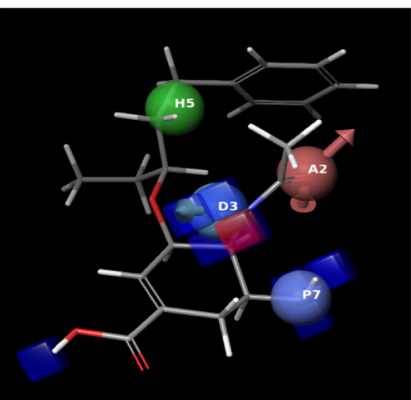

(a)

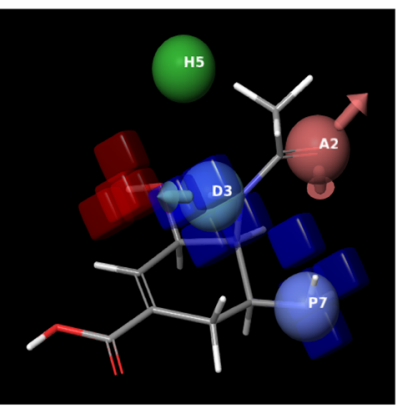

(b)
Fig. 4 Contour maps showing hydrogen bond donor effect on a active molecule and $\mathbf{b}$ inactive molecule

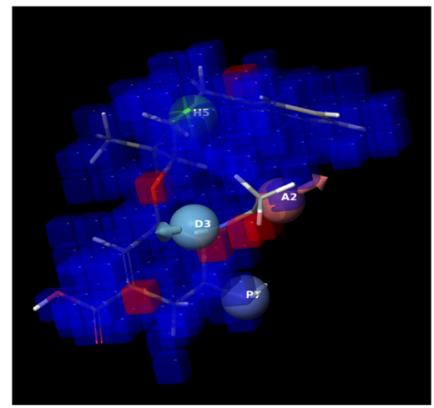

(a)

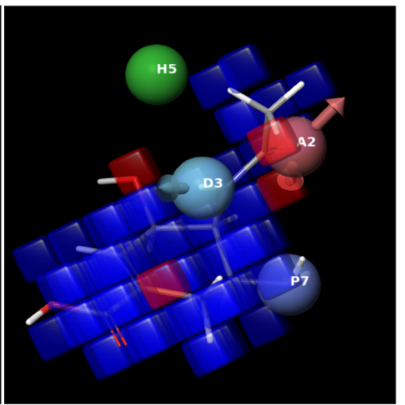

(b)
Fig. 5 Contour maps showing hydrophobic effect on a active molecule and $\mathbf{b}$ inactive molecule

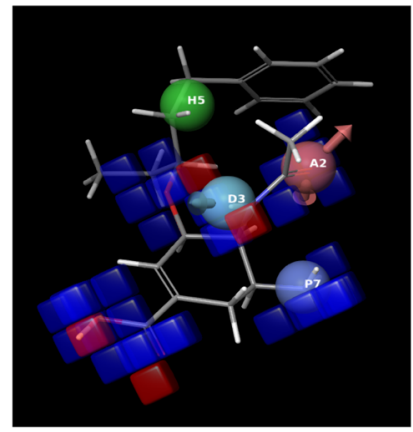

(a)

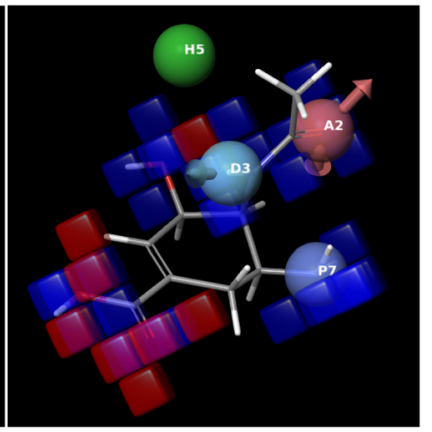

(b)
Fig. 6 Contour maps showing electron-withdrawing effect on a active molecule and $\mathbf{b}$ inactive molecule

which is present in case of active compound. Hence, this could be a reason for comparatively less hydrophobic nature of inactive compound than active compound.

The electron-withdrawing effect of both the ligands are shown in Fig. 6. This figure illustrates that the favorable regions lay near the positively charged, hydrogen bond acceptor and hydrogen bond donor features both active and inactive ligand. Additionally, the presence of more favorable blue regions near the carboxylic group of active compound (Fig. 6a) could enhance its biological activity against NA.

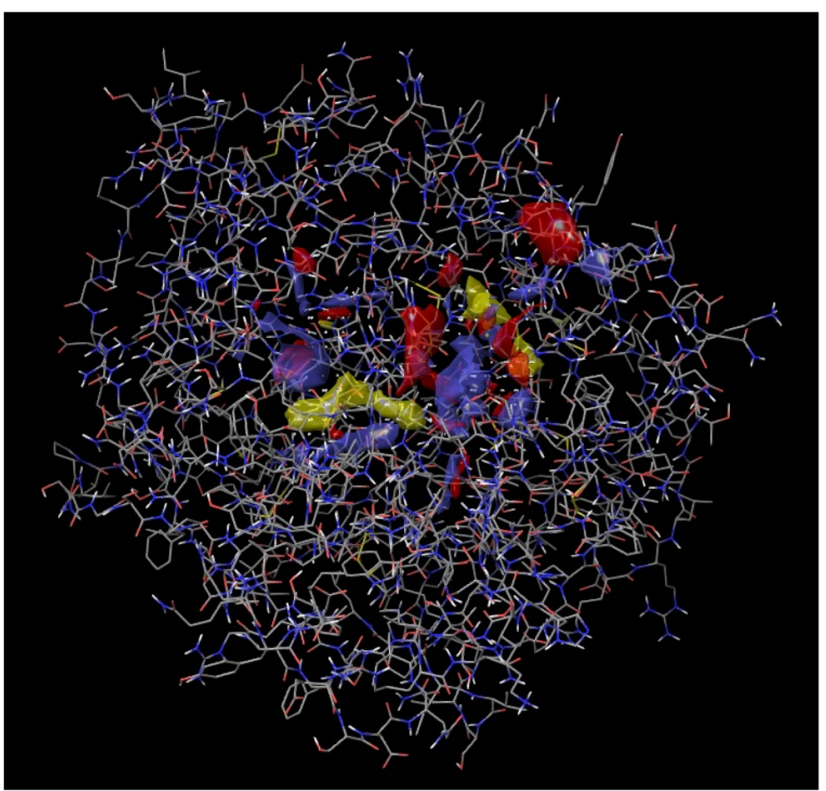

Fig. 7 Analysis of binding site residues using sitemap module

\section{Pharmacophore-Based Virtual Screening}

The virtual screening strategy based on pharmacophore model has been widely used in recent years and has shown many successive archives for lead identification [44]. In the present investigation, screening was conducted against Drug Bank database with the help of ADHP hypothesis as a search query. Initially, the PHASE database was created by applying Lipinski's filter. This yielded a total of 3000 molecules from the database of 8621 molecules. Subsequently, the screening was performed with the generated ADHP hypothesis that retreived 858 molecules as a match. Final screening was accomplished using the molecular docking algorithm.

\section{Molecular Docking}

The GLIDE module from Schrödinger Suite was utilized to perform molecular docking in the increasing order of complexity. The PHASE search query resulted in 858 molecules as matches for the common hypothesis (ADHP). To rank the screened ligands three stages of docking process such as, HTVS, SP, and XP were carried out. Prior to the docking process, the binding site residues in the NA structure were identified using Sitemap module implemented in the Maestro package. The results from the analysis highlight that 23 amino acid residues such as Arg 118, Glu 119, Leu 134, Asp 151, Arg 152, Arg 156, Trp 178, Ser 179, Asp 198, Asn 221, Ile 222, Arg 224, Glu 227, Ser 246, His 274, Glu 276, Glu 277, Arg 292, Asn 294, Asn 347, Arg 371, Tyr 406, and Glu 425 constituted the binding pocket of the NA structure (Fig. 7). It is noteworthy that, four amino acid residues namely, Arg 118, Glu 119, Arg 
292, and Arg 371 have been experimentally validated in the literature [45]. Further, we docked 858 ligands to the binding site of NA using the generated grid. Subsequently, $96.4 \%$ (827) of ligands were passed onto the next stage of SP glide docking. Finally, we filtered $42.07 \%$ (348) of ligands on the basis of docking and subjected to Glide XP docking simulation. This process was resulted 213 hit molecules having binding score more than oseltamivir. In particular, five FDA-approved drug molecules also showed significant NA inhibitory activity (Table 4). Moreover, the resultant hit molecules possessing a docking score more than oseltamivir were utilized for the AutoQSAR analysis to validate the 3D-QSAR model.

\section{Automated QSAR Workbench for 3D-QSAR Model Validation}

The set of hit molecules from XP docking were employed to investigate both 3D-QSAR model eminence as well as its accuracy in $\mathrm{pIC}_{50}$ value prediction. This analysis was performed by AutoQSAR algorithm [46]. It is an automated machine learning method that can build and validate a large number of QSAR models with different random training and test sets. The quality of the generated models is assessed with a score, computed by its training and test set molecules [47]. The top model with highest score of 0.952 was considered for the further analysis, $\mathrm{pIC}_{50}$ calculation. It is worth mentioning that the activity predicted by the best model was found to be similar to that of $\mathrm{pIC}_{50}$ value predicted by 3D-QSAR model. The result is depicted in Fig. 8. This clearly signifies the quality and accuracy of the generated 3D-QSAR model. Therefore, five FDA-approved hits resulted in the XP docking were further examined for its interaction pattern and absorption, distribution, metabolism and excretion (ADME) properties.

\section{Interaction Studies of Oseltamivir and Screened Hit Molecules}

The intermolecular interactions present in the complex structures of NA protein were analyzed using ligand-

Table 4 Glide scores and energy involvement of oseltamivir and screened hit molecules

\begin{tabular}{lllll}
\hline S. no. & Ligands & $\begin{array}{c}\text { Glide energy } \\
(\mathrm{kcal} / \mathrm{mol})\end{array}$ & $\begin{array}{c}\text { G score } \\
(\mathrm{kcal} / \mathrm{mol})\end{array}$ & $\begin{array}{c}\text { XP G score } \\
(\mathrm{kcal} / \mathrm{mol})\end{array}$ \\
\hline 1 & Oseltamivir & -42.387 & -4.882 & -4.882 \\
2 & DB01136 & -47.427 & -6.639 & -6.686 \\
3 & DB04861 & -44.474 & -6.471 & -6.471 \\
4 & DB00243 & -47.551 & -5.432 & -5.463 \\
5 & DB00722 & -51.563 & -5.369 & -5.49 \\
6 & DB06288 & -41.269 & -5.364 & -5.365 \\
\hline
\end{tabular}

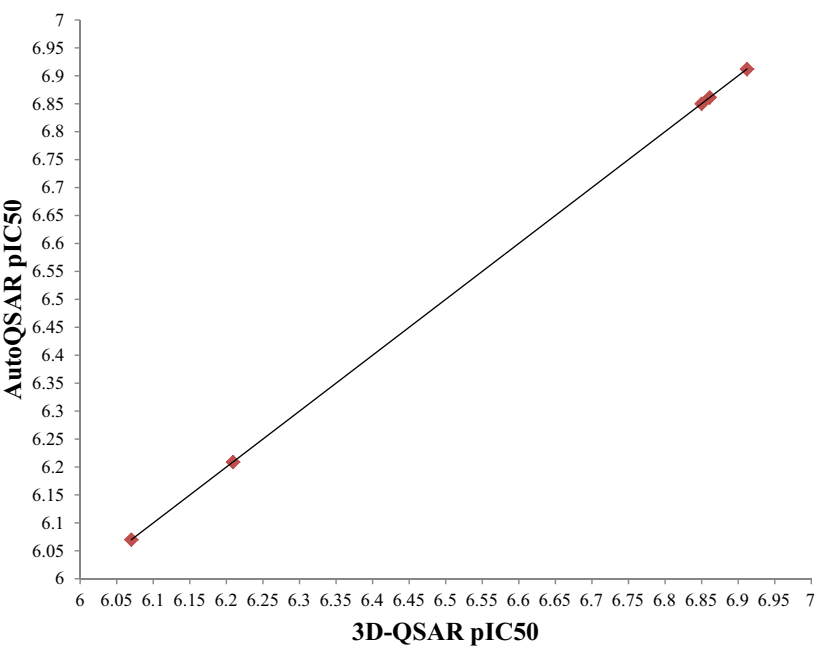

Fig. 8 Correlation between 3D-QSAR-predicted $\mathrm{pIC}_{50}$ and AutoQSAR-predicted $\mathrm{pIC}_{50}$ values

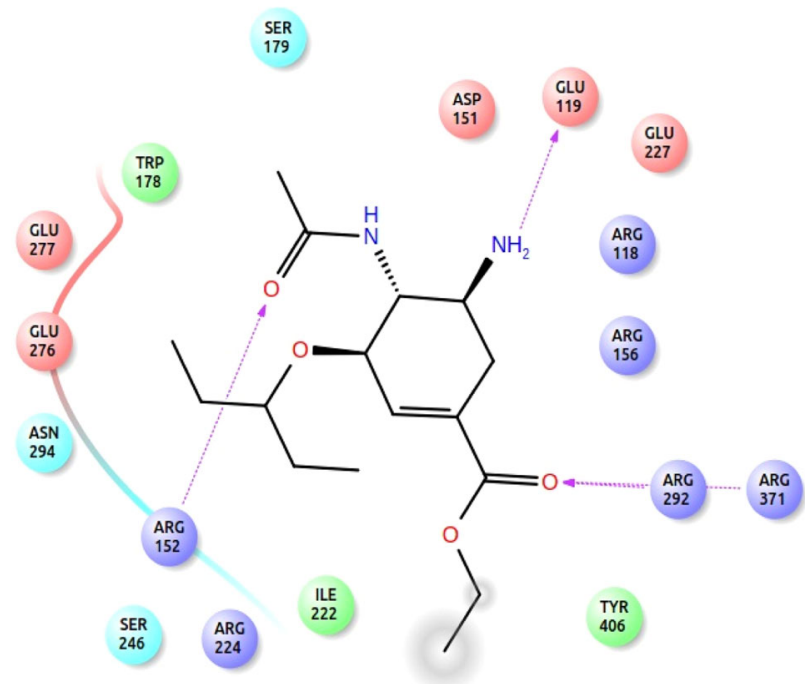

Fig. 9 Interaction profiles of neuraminidase with oseltamivir

interaction diagram (LID) of Schrödinger suite. The interaction diagram demonstrates the intermolecular interaction such as hydrogen bond (purple line), pi-pi stacking (green line), pi cation interaction (red line), and salt bridges (blue line). The crucial amino acid residues of NA contributing for hydrogen bond interaction with oseltamivir include Glu 119, Arg 152, Arg 292, and Arg 371. The binding pattern of oseltamivir with native NA protein is shown in Fig. 9. It illustrates that oxygen atom of oseltamivir forms hydrogen bonds with $\operatorname{Arg} 371, \operatorname{Arg} 292$, and Arg 152 and the amine group $\left(-\mathrm{NH}_{2}\right)$ of oseltamivir was found to form hydrogen bond with Glu 119 residue present in the binding pocket. Further, the interaction profile of five screened hit molecules from the docking study were also analyzed and compared with the oseltamivir binding profile (Fig. 10). The results 
(a)

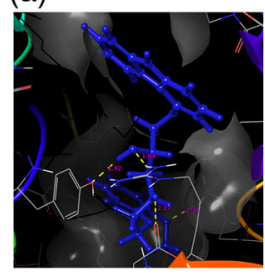

(d)

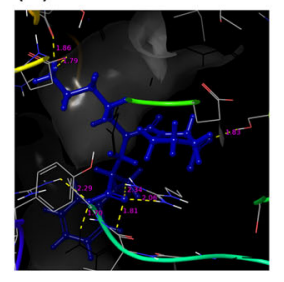

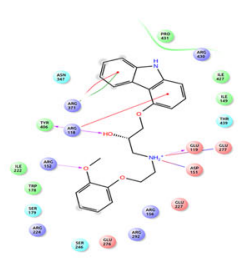

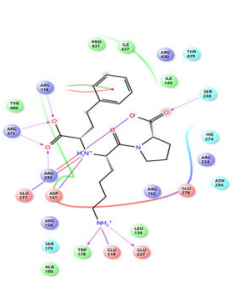

(b)
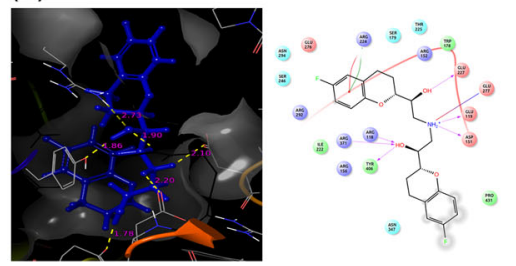

(e)

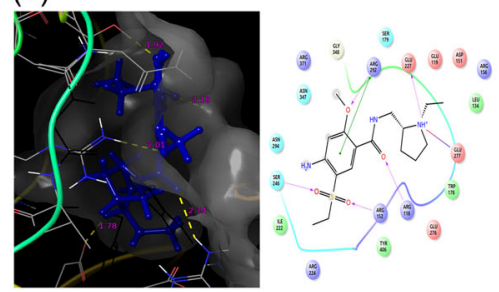

(c)

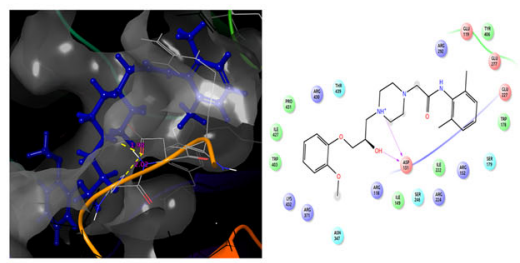

Fig. 10 Interaction profile of hit molecules a DB01136, b DB04861, c DB00243, d DB00722, and e DB06288 with neuraminidase protein

are depicted in the Table 5. It reveals that four molecules, namely, DB01136, DB04861, DB00722, and DB06288, from the hits were sharing similar kind of interaction profiles to that of the oseltamivir's binding pattern. In addition, the hydrogen bond distance between hit molecules and key residues were found to be within the acceptable range $(<3$ $\AA$ ). For instance, the hit molecule DB00722 is forming hydrogen bond with conserved residues such as Arg 118, Trp 178, Arg 292, and Arg 371. Along with these residues, hydrogen bonding with framework residue Glu 227 was also found. In addition, other three hit molecules, DB01136, DB04861, and DB06288, were also found exhibiting similar kind of interactions. Therefore, these molecules were further examined with respect to their drug likeliness property using Qikprop program of Schrödinger Suite.

\section{ADME Properties of Hit Molecules}

ADME properties of the four molecules were calculated using Qikprop program [48-50]. Qikprop predicts pharmaceutically relevant 49 descriptors. It also provides the range to compare with the molecular properties of $95 \%$ known drugs. The values of this descriptor for all the four screened compounds are depicted in Table 6. The descriptor \#stars indicates the number of properties that fall outside the recommended range. Therefore, a lower number of \#stars denotes the better drug-like molecule. It is clear from the table that all the compounds were found to have the \#stars value of zero, which means that all the 49 pharmaceutically relevant descriptors lies in the recommended range to that of known drugs. The compounds were then checked for another descriptor, CNS, which predicts the central nervous system activity of each compound. For instance, the CNS value lies between -2 (inactive) and +2 (active). It is noted that two hit compounds namely, DB00722 (lisinopril) and
DB06288 (amisulpride) possess CNS value of -2 indicating that it is inactive. Further, the descriptor sets such as QPlogKp, QPlogBB, QPlogS, QPlogPo/w, QPlogPw, and QPlogPoct were also analyzed and found to present within the acceptable range. Particularly, lisinopril (angiotensinconverting enzyme (ACE) inhibitor) is found to form similar kind of interaction profile as that of oseltamivir.

Lisinopril belongs to a group of medicines called ACE inhibitors. One of the most common side effects of lisinopril is a dry cough. Other uncommon side effects include hypotension, chest pain shivering, etc [51]. Despite its notable side effects, anti-TNF treatment might be actually beneficial because of a critical element of influenza infection outcome, lung inflammation. Of note, lisinopril was reported to have anti-inflammatory effects via suppression of the pro-inflammatory cytokines such as TNF- $\alpha$ production [52]. However, this mechanism may be closely related to symptom relief without significant reduction of viral load. Thus, we hope that lisinopril treatment with concomitant immunomodulatory drugs may contribute to the clinical benefits.

\section{Docking Studies of Hit Compound with Mutants}

To strengthen our study, the inhibitory activity of the lead molecule was also tested against the mutant NA structures using XP GLIDE docking. The mutant positions such as H274Y, R292K, E119G, N294S, D179E, I223R, and I221L were taken into consideration for our study. The glide scores of oseltamivir against each mutant were taken as the threshold for our investigation. It is noteworthy to mention that the binding efficacy of lisinopril is significantly higher than reference drug in all the studied structures (Table 7). For instance, the glide score of oseltamivir against mutants is between -3.329 and $-4.644 \mathrm{kcal} / \mathrm{mol}$, whereas for the hit 
Table 5 Analysis of intermolecular interaction of screened hit molecules with neuraminidase protein

\begin{tabular}{|c|c|c|c|c|}
\hline S. no. & Ligands & Types of Interaction & Interacting atoms of protein-ligand complex & Distance $(\AA)$ \\
\hline \multirow[t]{4}{*}{1.} & \multirow[t]{4}{*}{ Oseltamivir } & \multirow[t]{4}{*}{ H-bond } & $\operatorname{Arg} 292 \cdots \operatorname{Lig}(\mathrm{O})$ & 2.344 \\
\hline & & & $\operatorname{Arg} 371 \cdots \operatorname{Lig}(\mathrm{O})$ & 1.826 \\
\hline & & & $\operatorname{Arg} 152 \cdots \operatorname{Lig}(\mathrm{O})$ & 2.1483 \\
\hline & & & Glu $119 \cdots \operatorname{Lig}\left(\mathrm{NH}_{2}\right)$ & 2.0835 \\
\hline \multirow[t]{9}{*}{2.} & \multirow[t]{9}{*}{ DB01136 } & \multirow[t]{4}{*}{ H-bond } & $\operatorname{Lig}(\mathrm{HO}) \cdots \operatorname{Tyr} 406$ & 1.918 \\
\hline & & & $\operatorname{Arg} 118 \cdots \operatorname{Lig}(\mathrm{HO})$ & 1.842 \\
\hline & & & $\operatorname{Arg} 152 \cdots \operatorname{Lig}(\mathrm{O})$ & 2.339 \\
\hline & & & Glu $119 \cdots \operatorname{Lig}\left(\mathrm{NH}_{2}^{+}\right)$ & 2.167 \\
\hline & & \multirow[t]{2}{*}{ Salt bridges } & $\operatorname{Lig}\left(\mathrm{NH}_{2}^{+}\right) \cdots$ Glu 277 & 4.508 \\
\hline & & & Asp $151 \cdots \operatorname{Lig}\left(\mathrm{NH}_{2}^{+}\right)$ & 4.497 \\
\hline & & \multirow[t]{2}{*}{ Pi cation } & Ag 118 & 5.769 \\
\hline & & & Arg 371 & 3.425 \\
\hline & & $\mathrm{Pi}-\mathrm{Pi}$ & Arg 371 & 3.563 \\
\hline \multirow[t]{9}{*}{3.} & \multirow[t]{9}{*}{ DB04861 } & \multirow[t]{6}{*}{ H-bond } & $\operatorname{Lig}(\mathrm{HO}) \cdots$ Glu 227 & 1.782 \\
\hline & & & Glu $119 \cdots \operatorname{Lig}\left(\mathrm{H}_{2}{ }^{+} \mathrm{N}\right)$ & 2.203 \\
\hline & & & Asp $151 \cdots \operatorname{Lig}\left(\mathrm{H}_{2}^{+} \mathrm{N}\right)$ & 2.098 \\
\hline & & & $\operatorname{Arg} 371 \cdots \operatorname{Lig}(\mathrm{HO})$ & 2.725 \\
\hline & & & $\operatorname{Lig}(\mathrm{HO}) \cdots \operatorname{Arg} 118$ & 1.898 \\
\hline & & & $\operatorname{Lig}(\mathrm{OH}) \cdots \operatorname{Tyr} 406$ & 1.861 \\
\hline & & Salt bridges & Glu $277 \cdots \operatorname{Lig}\left(\mathrm{NH}_{2}{ }^{+}\right)$ & 4.664 \\
\hline & & Pi cation & Arg 224 & 5.795 \\
\hline & & $\mathrm{Pi}-\mathrm{Pi}$ & Arg 224 & 5.345 \\
\hline \multirow[t]{2}{*}{4.} & \multirow[t]{2}{*}{ DB00243 } & \multirow[t]{2}{*}{ H-bond } & $\operatorname{Lig}\left(\mathrm{H}^{+} \mathrm{N}\right) \cdots$ Asp 151 & 1.977 \\
\hline & & & $\operatorname{Lig}(\mathrm{HO}) \cdots \operatorname{Arg} 151$ & 2.021 \\
\hline \multirow[t]{13}{*}{5.} & \multirow[t]{13}{*}{ DB00722 } & \multirow[t]{7}{*}{ H-bond } & $\operatorname{Arg} 118 \cdots \operatorname{Lig}\left(\mathrm{O}^{-}\right)$ & 2.289 \\
\hline & & & $\operatorname{Lig}\left(\mathrm{O}^{-}\right) \cdots \operatorname{Arg} 371$ & 1.697 \\
\hline & & & $\operatorname{Lig}\left(\mathrm{O}^{-}\right) \cdots \operatorname{Arg} 371$ & 1.813 \\
\hline & & & $\operatorname{Lig}(O) \cdots \operatorname{Arg} 292$ & 2.343 \\
\hline & & & $\operatorname{Trp} 178 \cdots \operatorname{Lig}\left(\mathrm{H}_{3}{ }^{+} \mathrm{N}\right)$ & 1.857 \\
\hline & & & $\operatorname{Lig}\left(\mathrm{H}_{3}{ }^{+} \mathrm{N}\right) \cdots$ Glu 227 & 1.786 \\
\hline & & & $\operatorname{Lig}(\mathrm{O}) \cdots \operatorname{Ser} 246$ & 1.832 \\
\hline & & \multirow[t]{4}{*}{ Salt bridges } & $\operatorname{Arg} 292 \cdots \operatorname{Lig}\left(\mathrm{O}^{-}\right)$ & 4.099 \\
\hline & & & Glu $277 \cdots \operatorname{Lig}\left(\mathrm{H}_{2} \mathrm{~N}^{+}\right)$ & 4.635 \\
\hline & & & Asp $151 \cdots \operatorname{Lig}\left(\mathrm{H}_{2} \mathrm{~N}^{+}\right)$ & 4.245 \\
\hline & & & Glu $119 \cdots \operatorname{Lig}\left(\mathrm{NH}_{3}^{+}\right)$ & 3.409 \\
\hline & & Pi cation & Arg 118 & 5.682 \\
\hline & & $\mathrm{Pi}-\mathrm{Pi}$ & Arg 118 & 4.9306 \\
\hline \multirow[t]{7}{*}{6.} & \multirow[t]{7}{*}{ DB06288 } & \multirow[t]{5}{*}{ H-bond } & $\operatorname{Arg} 292 \cdots \operatorname{Lig}(\mathrm{O})$ & 2.007 \\
\hline & & & Glu $227 \cdots \operatorname{Lig}\left(\mathrm{NH}^{+}\right)$ & 1.777 \\
\hline & & & $\operatorname{Arg} 118 \cdots \operatorname{Lig}(\mathrm{O})$ & 2.742 \\
\hline & & & $\operatorname{Arg} 152 \cdots \operatorname{Lig}(\mathrm{O})$ & 2.184 \\
\hline & & & Ser $246 \cdots \operatorname{Lig}(O)$ & 1.916 \\
\hline & & Salt bridges & Glu $277 \cdots \operatorname{Lig}\left(\mathrm{NH}^{+}\right)$ & 4.083 \\
\hline & & $\mathrm{Pi}-\mathrm{Pi}$ & Arg 292 & 4.914 \\
\hline
\end{tabular}

compound the glide score varies between -4.757 and $-7.140 \mathrm{kcal} / \mathrm{mol}$. Further the intermolecular interactions were analyzed to gain an insight into the binding of hit compound. The results are shown in Fig. 11 and the details of intermolecular interactions were listed in Table 8. It is interesting to note that the hit compound, lisinopril is able to 
372

Cell Biochemistry and Biophysics (2018) 76:357-376

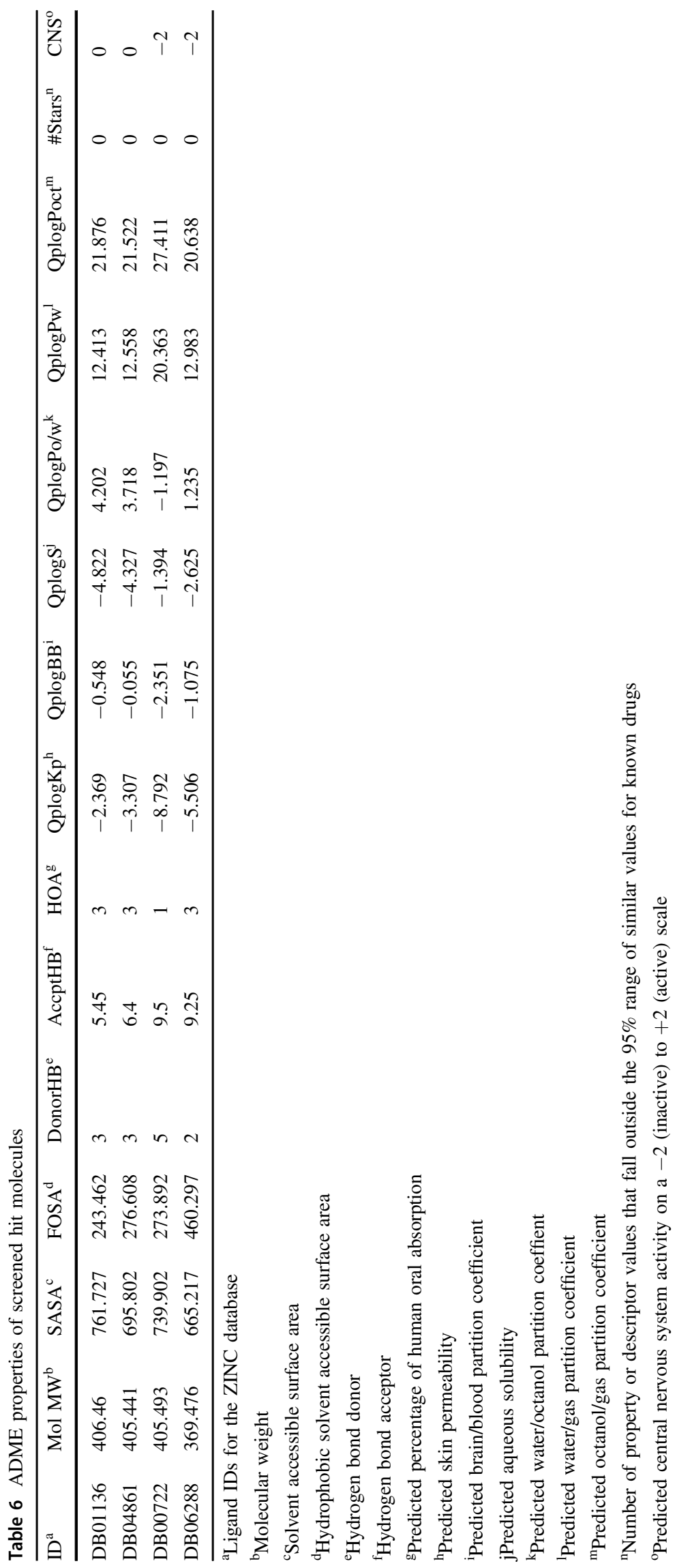

基 Springer 
form hydrogen bonds with key residues such as Arg 292, Arg 371, Arg 152, Asp 151, and Arg 118 even in NA mutants. Interaction with these residues is the predominant factor for orientation and stabilization of NA-mutant complex with hit molecule.

\section{Conclusions}

In the present investigation, the previously reported carbocylic influenza NA inhibitors with known inhibitory

Table 7 Glide score of oseltamivir and lisinopril with the mutated strains of influenza A virus

\begin{tabular}{lllll}
\hline S. no. & Mutation & PDB code & \multicolumn{2}{c}{ Glide score (kcal/mol) } \\
\cline { 3 - 5 } & & & Oseltamivir & Lisinopril \\
\hline 1. & H274Y & $4 \mathrm{HZZ}$ & -4.644 & -6.054 \\
2. & R292K & 1L7H & -4.252 & -4.757 \\
3. & E119G & $1 \mathrm{~L} 74$ & -4.069 & -5.690 \\
4. & N294S & $3 \mathrm{CL} 2$ & -4.335 & -6.675 \\
5. & I223R & $4 \mathrm{~B} 7 \mathrm{~N}$ & -3.329 & -7.140 \\
6. & D179E & $3 \mathrm{~K} 39$ & -3.761 & -6.063 \\
7. & I221L & $4 \mathrm{CPM}$ & -4.398 & -6.699 \\
\hline
\end{tabular}

(a)

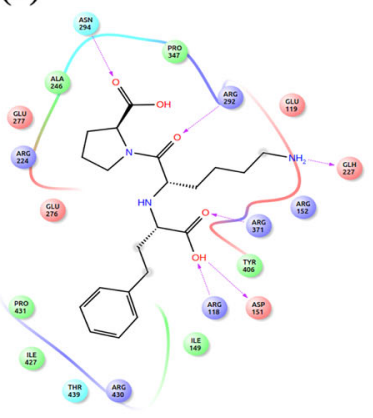

(e)

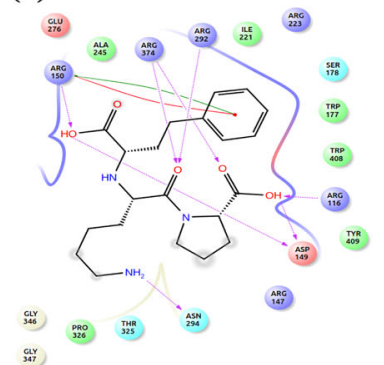

(b)

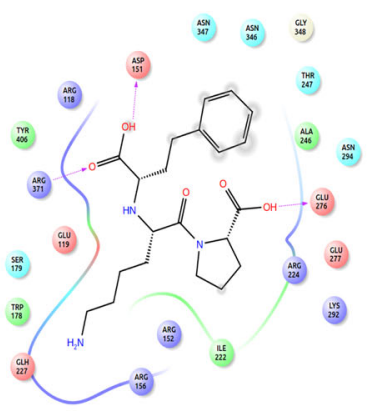

(f)

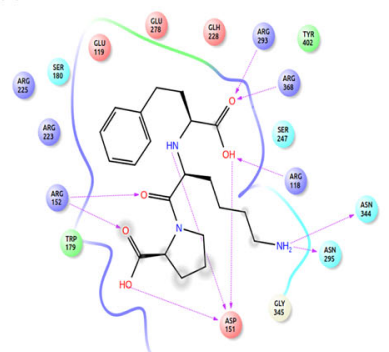

potential were explored for drug repurposing strategy. The best pharmacophore model (ADHP) generated consisted of one hydrogen bond acceptor (A), one hydrogen bond donor (D), one hydrophobic group $(\mathrm{H})$, and one positively charged group $(\mathrm{P})$. The goodness of the pharmacophore model was evaluated using enrichment analysis. In addition, the pharmacophore features obtained were then correlated with highly prognostic atom-based 3D-QSAR model. A highly predictive and significant atom-based 3D-QSAR model with $R^{2}$ value of 0.9866 and $Q^{2}$ value of 0.7629 was generated. Further, the hydrogen bond donor effect, hydrophobic effect and electron-withdrawing effect on most active and most inactive compounds were analyzed. The hits were retrieved by combining both $\mathrm{CPH}$ and 3D-QSAR model. This process captured set of hit molecules, which were further scrutinized based on three consecutive docking runs and drug likeliness analysis. Moreover, AutoQSAR study is also performed to examine the generated 3D-QSAR model accuracy. The results from our study emphasize that lisinopril (DB00722) has the capability to exhibit better inhibitory activity against NA than available drugs. Overall, it is possible that mortality could be reduced by treating patients with immunomodulatory drugs. With the enormous developments of vaccines and anti-virals in the recent years to manage severe seasonal and pandemic influenza, the need for a new approach of this type is obvious and inescapable.

Fig. 11 2D interaction diagram of lisinopril with NA mutants a H274Y, b R292K, c E119G, d N294S, e D179E, f I223R, and e I221L 
Table 8 Intermolecular interaction of compound lisinopril with NA mutants

\begin{tabular}{|c|c|c|c|c|}
\hline S. no. & Mutation & $\begin{array}{l}\text { Type of } \\
\text { interaction }\end{array}$ & $\begin{array}{l}\text { Interacting atoms of } \\
\text { protein-ligand } \\
\text { complex }\end{array}$ & Distance $(\AA)$ \\
\hline \multirow[t]{6}{*}{1.} & \multirow[t]{6}{*}{$\mathrm{H} 274 \mathrm{Y}$} & \multirow[t]{6}{*}{ H-bond } & Asn $294 \cdots \operatorname{Lig}(\mathrm{O})$ & 2.107 \\
\hline & & & $\operatorname{Arg} 292 \cdots \operatorname{Lig}(O)$ & 1.927 \\
\hline & & & Gln $227 \cdots \operatorname{Lig}\left(\mathrm{H}_{2} \mathrm{~N}\right)$ & 2.211 \\
\hline & & & $\operatorname{Arg} 371 \cdots \operatorname{Lig}(\mathrm{O})$ & 2.115 \\
\hline & & & Asp $151 \cdots \operatorname{Lig}(\mathrm{HO})$ & 1.749 \\
\hline & & & $\operatorname{Arg} 118 \cdots \operatorname{Lig}(\mathrm{O})$ & 2.1223 \\
\hline \multirow[t]{3}{*}{2.} & \multirow[t]{3}{*}{ R292K } & \multirow[t]{3}{*}{ H-bond } & $\operatorname{Arg} 371 \cdots \operatorname{Lig}(\mathrm{O})$ & 2.069 \\
\hline & & & Asp $151 \cdots \operatorname{Lig}(\mathrm{HO})$ & 1.6043 \\
\hline & & & Glu $276 \cdots \operatorname{Lig}(\mathrm{HO})$ & 1.969 \\
\hline \multirow[t]{6}{*}{3.} & \multirow[t]{6}{*}{ E119G } & \multirow[t]{6}{*}{ H-bond } & $\operatorname{Arg} 292 \cdots \operatorname{Lig}(\mathrm{O})$ & 2.198 \\
\hline & & & $\operatorname{Arg} 371 \cdots \operatorname{Lig}(\mathrm{O})$ & 1.929 \\
\hline & & & $\operatorname{Trp} 178 \cdots \operatorname{Lig}\left(\mathrm{H}_{2} \mathrm{~N}\right)$ & 1.987 \\
\hline & & & Asp $151 \cdots \operatorname{Lig}\left(\mathrm{H}_{2} \mathrm{~N}\right)$ & 2.319 \\
\hline & & & $\operatorname{Trp} 178 \cdots \operatorname{Lig}\left(\mathrm{H}_{2} \mathrm{~N}\right)$ & 2.036 \\
\hline & & & $\operatorname{Arg} 152 \cdots \operatorname{Lig}(\mathrm{O})$ & 1.939 \\
\hline \multirow[t]{9}{*}{4.} & \multirow[t]{9}{*}{$\mathrm{N} 294 \mathrm{~S}$} & \multirow[t]{8}{*}{ H-bond } & $\operatorname{Lig}(\mathrm{HO}) \cdots$ Glu 277 & 1.711 \\
\hline & & & $\operatorname{Trp} 178 \cdots \operatorname{Lig}\left(\mathrm{H}_{2} \mathrm{~N}\right)$ & 1.975 \\
\hline & & & $\operatorname{Lig}(\mathrm{HO}) \cdots \operatorname{Arg} 118$ & 1.792 \\
\hline & & & $\operatorname{Lig}(\mathrm{OH}) \cdots \operatorname{Tyr} 406$ & 1.790 \\
\hline & & & $\operatorname{Arg} 371 \cdots \operatorname{Lig}(\mathrm{O})$ & 2.358 \\
\hline & & & $\operatorname{Arg} 292 \cdots \operatorname{Lig}(O)$ & 2.748 \\
\hline & & & $\operatorname{Arg} 292 \cdots \operatorname{Lig}(O)$ & 2.313 \\
\hline & & & Asp $151 \cdots \operatorname{Lig}(\mathrm{HN})$ & 1.7333 \\
\hline & & Salt bridge & Arg 371 & 3.369 \\
\hline \multirow[t]{10}{*}{5.} & \multirow[t]{10}{*}{ D179E } & \multirow[t]{8}{*}{ H-bond } & $\operatorname{Arg} 150 \cdots \operatorname{Lig}(\mathrm{OH})$ & 1.988 \\
\hline & & & $\operatorname{Arg} 374 \cdots \operatorname{Lig}(\mathrm{O})$ & 2.593 \\
\hline & & & $\operatorname{Arg} 374 \cdots \operatorname{Lig}(\mathrm{O})$ & 1.743 \\
\hline & & & $\operatorname{Arg} 292 \cdots \operatorname{Lig}(\mathrm{O})$ & 1.704 \\
\hline & & & $\operatorname{Arg} 116 \cdots \operatorname{Lig}(\mathrm{HO})$ & 1.905 \\
\hline & & & Asp $149 \cdots \operatorname{Lig}(\mathrm{HO})$ & 1.676 \\
\hline & & & Asp $149 \cdots \operatorname{Lig}(\mathrm{HO})$ & 1.538 \\
\hline & & & Asn $294 \cdots \operatorname{Lig}\left(\mathrm{H}_{2} \mathrm{~N}\right)$ & 2.218 \\
\hline & & $\mathrm{Pi}-\mathrm{Pi}$ & Arg 150 & 5.248 \\
\hline & & Pi cation & Arg 150 & 5.342 \\
\hline \multirow[t]{10}{*}{6.} & \multirow[t]{10}{*}{ I223R } & \multirow[t]{10}{*}{ H-bond } & $\operatorname{Arg} 293 \cdots \operatorname{Lig}(\mathrm{O})$ & 2.788 \\
\hline & & & $\operatorname{Arg} 368 \cdots \operatorname{Lig}(\mathrm{O})$ & 2.257 \\
\hline & & & $\operatorname{Arg} 118 \cdots \operatorname{Lig}(\mathrm{HO})$ & 2.7008 \\
\hline & & & Asn $344 \cdots \operatorname{Lig}\left(\mathrm{H}_{2} \mathrm{~N}\right)$ & 1.738 \\
\hline & & & Asn $295 \cdots \operatorname{Lig}\left(\mathrm{H}_{2} \mathrm{~N}\right)$ & 2.105 \\
\hline & & & Asp $151 \cdots \operatorname{Lig}(\mathrm{HO})$ & 2.019 \\
\hline & & & Asp $151 \cdots \operatorname{Lig}(\mathrm{HN})$ & 1.764 \\
\hline & & & Asp $151 \cdots \operatorname{Lig}(\mathrm{HO})$ & 1.865 \\
\hline & & & $\operatorname{Arg} 152 \cdots \operatorname{Lig}(\mathrm{O})$ & 2.1086 \\
\hline & & & $\operatorname{Arg} 152 \cdots \operatorname{Lig}(\mathrm{O})$ & 2.052 \\
\hline
\end{tabular}

Table 8 (continued)

\begin{tabular}{|c|c|c|c|c|}
\hline S. no. & Mutation & $\begin{array}{l}\text { Type of } \\
\text { interaction }\end{array}$ & $\begin{array}{l}\text { Interacting atoms of } \\
\text { protein-ligand } \\
\text { complex }\end{array}$ & Distance $(\AA)$ \\
\hline \multirow[t]{7}{*}{7.} & \multirow[t]{7}{*}{$\mathrm{I} 221 \mathrm{~L}$} & \multirow[t]{5}{*}{ H-bond } & Glu $275 \cdots \operatorname{Lig}\left(\mathrm{H}_{2} \mathrm{~N}\right)$ & 1.839 \\
\hline & & & Glu $274 \cdots \operatorname{Lig}\left(\mathrm{H}_{2} \mathrm{~N}\right)$ & 1.704 \\
\hline & & & $\operatorname{Trp} 176 \cdots \operatorname{Lig}(\mathrm{HO})$ & 1.811 \\
\hline & & & Arg $291 \cdots \operatorname{Lig}(\mathrm{O})$ & 2.388 \\
\hline & & & Arg $373 \cdots \operatorname{Lig}(\mathrm{O})$ & 2.659 \\
\hline & & \multirow[t]{2}{*}{$\mathrm{Pi}-\mathrm{Pi}$} & $\operatorname{Trp} 407$ & 5.412 \\
\hline & & & Arg 115 & 5.499 \\
\hline
\end{tabular}

Acknowledgements We gratefully acknowledge Vellore Institute of Technology University, Vellore for the support through Seed Grant for Research.

\section{Compliance with ethical standards}

Conflict of interest The authors declare that they have no conflict of interest.

\section{References}

1. Li, X. B., Wang, S. Q., Xu, W. R., Wang, R. L., \& Chou, K. C. (2011). Novel inhibitor design for hemagglutinin against H1N1 influenza virus by core hopping method. PLoS ONE, 6, e28111.

2. Mukhtar, M. M., Rasool, S. T., Song, D., Zhu, C., Hao, Q., \& Zhu, Y. (2007). Origin of highly pathogenic H5N1 avian influenza virus in China and genetic characterization of donor and recipient viruses. Journal of General Virology, 88, 3094-3099.

3. Matrosovich, M. N., Matrosovich, T. Y., Gray, T., Roberts, N. A., \& Klenk, H. (2004). Neuraminidase is important for the initiation of influenza virus infection in human airway epithelium. Journal of Virology, 78, 12665-12667.

4. Su, Y., Yang, H. Y., Zhang, B. J., Jia, H. L., \& Tien, P. (2008). Analysis of a point mutation in $\mathrm{H} 5 \mathrm{~N} 1$ avian influenza virus hemagglutinin in relation to virus entry into live mammalian cells. Archives of Virology, 153, 2253-2261.

5. Karthick, V., \& Ramanathan, K. (2014). Insight into the oseltamivir resistance R292K mutation in $\mathrm{H} 5 \mathrm{~N} 1$ influenza virus: a molecular docking and molecular dynamics approach. Cell Biochemistry and Biophysics, 68, 291-299.

6. Bauer, K., Richter, M., Wutzler, P., \& Schmidtke, M. (2009). Different neuraminidase inhibitor susceptibilities of human H1N1, $\mathrm{H} 1 \mathrm{~N} 2$, and H3N2 influenza A viruses isolated in Germany from 2001 to 2005/06. Antiviral Research, 82, 34-41.

7. Hurt, A. C., Holien, J. K., Parker, M., \& Barr, I. G. (2009). Oseltamivir resistance and the H274Y neuraminidase mutation in seasonal, pandemic and highly pathogenic influenza viruses. Drugs, 69, 2523-2531.

8. Shobugawa, Y., Saito, R., Sato, I., Kawashima, T., Dapat, C., Dapat, I. C., Kondo, H., Suzuki, Y., Saito, K., \& Suzuki, H. (2012). Clinical effectiveness of neuraminidase inhibitor oseltamivir, zanamivir, laninamivir, and peramivir for treatment of influenza $\mathrm{A}(\mathrm{H} 3 \mathrm{~N} 2)$ and $\mathrm{A}(\mathrm{H} 1 \mathrm{~N} 1)$ pdm09 infection: an observational study in the 2010-2011 influenza season in Japan. Journal of Infection and Chemotherapy, 18, 858-864. 
9. Pizzorno, A., Abed, Y., Plante, P. L., Carbonneau, J., Baz, M., Hamelin, M. E., Corbeil, J., \& Boivin, G. (2014). Evolution of oseltamivir resistance mutations in influenza $\mathrm{A}(\mathrm{H} 1 \mathrm{~N} 1)$ and $\mathrm{A}$ (H3N2) viruses during selection in experimentally infected mice. Antimicrobial Agents and Chemotherapy, 58, 6398-6405.

10. Wu, N. C., Young, A. P., Dandekar, S., Wijersuriya, H., AlMawsawi, L. Q., Wu, T. T., \& Sun, R. (2013). Systematic identification of $\mathrm{H} 274 \mathrm{Y}$ compensatory mutations in influenza A virus neuraminidase by high-throughput screening. Journal of Virology, 87, 1193-1199.

11. Yen, H. L., McKimm-Breschkin, J. L., Choy, K. T., Wong, D. D. Y., Cheung, P. P. H., Zhou, J., Ng, I. H., Zhu, H., Webby, R. J., Guan, Y., Webster, R. G., \& Peirisa, J. S. M. (2013). Resistance to neuraminidase inhibitors conferred by an R292K mutation in a human influenza virus H7N9 isolate can be masked by a mixed R/ $\mathrm{K}$ viral population. MBio, 4, e00396-13.

12. McKimm-Breschkin, J. L. (2012). Influenza neuraminidase inhibitors: antiviral action and mechanisms of resistance. Influenza and Other Respiratory Viruses, 7, 25-36.

13. Escuret, V., Collins, P. J., Casalegno, J. S., Vachieri, S. G., Cattle, N., Ferraris, O., Sabatier, M., Frobert, E., Caro, V., Skehel, J. J., Gamblin, S., Valla, F., Valette, M., Ottmann, M., McCauley, J. W., Daniels, R. S., \& Lina, B. (2014). A novel I221L substitution in neuraminidase confers high-level resistance to oseltamivir in influenza B viruses. The Journal of Infectious Diseases, 210, $1260-1269$.

14. LeGoff, J., Rousset, D., Abou-Jaoudé, G., Scemla, A., Ribaud, P., Mercier-Delarue, S., Caro, V., Enouf, V., Simon, F., Molina, J., \& van der Werf, S. (2012). I223R mutation in influenza A(H1N1) pdm09 neuraminidase confers reduced susceptibility to oseltamivir and zanamivir and enhanced resistance with H275Y. PLoS ONE, 7, e37095.

15. Cai, Z., Zhang, G., Tang, B., Liu, Y., Fu, X., \& Zhang, X. (2015). Promising anti-influenza properties of active constituent of Withaniasomnifera ayurvedic herb in targeting neuraminidase of H1N1 influenza: computational study. Cell Biochemistry and Biophysics, 72, 727-739.

16. Moonsamy, S., Bhakat, S., Ramesh, M., \& Soliman, M. E. (2017). Identification of binding mode and prospective structural features of novel Nef protein inhibitors as potential anti-HIV drugs. Cell Biochemistry and Biophysics, 75, 49-64.

17. Shoichet, B. K. (2004). Virtual screening of chemical libraries. Nature, 432, 862-865.

18. Karthick, V., Ramanathan, K., Shanthi, V., \& Rajasekaran, R. (2013). Identification of potential inhibitors of H5N1 influenza A virus neuraminidase by ligand-based virtual screening approach. Cell Biochemistry and Biophysics, 66, 657-669.

19. James, N., \& Ramanathan, K. (2017). Discovery of potent ALK inhibitors using pharmacophore-informatics strategy. Cell Biochemistry and Biophysics, 6, 1-4.

20. Chaudhari, P., \& Bari, S. (2016). In silico exploration of c-KIT inhibitors by pharmaco-informatics methodology: pharmacophore modeling, 3D QSAR, docking studies, and virtual screening. Molecular Diversity, 20, 41-53.

21. Sinha, S., Goyal, S., Somvanshi, P., \& Grover, A. (2017). Mechanistic insights into the binding of class IIa HDAC inhibitors toward spinocerebellar ataxia type-2: a 3D-QSAR and pharmacophore modeling approach. Frontiers in Neuroscience, 10, 606.

22. Bhadauriya, A., Dhoke, G. V., Gangwal, R. P., Damre, M. V., \& Sangamwar, A. T. (2013). Identification of dual acetyl-CoA carboxylases 1 and 2 inhibitors by pharmacophore based virtual screening and molecular docking approach. Molecular Diversity, 17, 139-149.

23. Kim, C. U., Lew, W., Williams, M. A., Wu, H., Zhang, L., Chen, X., Escarpe, P. A., Mendel, D. B., Laver, W. G., \& Stevens, R. C. (1998). Structure-activity relationship studies of novel carbocyclic influenza neuraminidase inhibitors. Journal of Medicinal Chemistry, 41, 2451-2460.

24. Halgren, T. A., Murphy, R. B., Friesner, R. A., Beard, H. S., Frye, L. L., Pollard, W. T., \& Banks, J. L. (2004). Glide: a new approach for rapid, accurate docking and scoring. 2. Enrichment factors in database screening. Journal of Medicinal Chemistry, 47, 1750-1759.

25. Berman, H. M., Westbrook, J., Feng, Z., Gilliland, G., Bhat, T. N., \& Weissig, H. (2000). The protein data bank. Nucleic Acid Research, 28, 235-242.

26. Vavricka, C. J., Li, Q., Wu, Y., Qi, J., Wang, M., Liu, Y., Gao, F., Liu, J., Feng, E., He, J., Wang, J., Liu, H., Jiang, H., \& Gao, G. F. (2011). Structural and functional analysis of laninamivir and its octanoate prodrug reveals group specific mechanisms for influenza NA inhibition. PLoS Pathog, 7, e1002249.

27. Vass, M., Schmidt, É., Horti, F., \& Keserú, G. M. (2014). Virtual fragment screening on GPCRs: a case study on dopamine D3 and histamine H4 receptors. European Journal of Medicinal Chemistry, 77, 38-46.

28. Yewale, S. B., Ganorkar, S. B., Baheti, K. G., \& Shelke, R. U. (2012). Novel 3-substituted-1-aryl-5-phenyl-6-anilinopyrazolo [3,4-d]pyrimidin-4-ones: docking, synthesis and pharmacological evaluation as a potential anti-inflammatory agents. Bioorganic \& Medicinal Chemistry Letters, 22, 6616-6620.

29. Aparna, V., Dineshkumar, K., Mohanalakshmi, N., Velmurugan, D., \& Hopper, W. (2014). Identification of natural compound inhibitors for multidrug efflux pumps of Escherichia coli and Pseudomonas aeruginosa using in silico high-throughput virtual screening and in vitro validation. PLOS ONE, 9, e101840.

30. Ramar, V., \& Pappu, S. (2016). Exploring the inhibitory potential of bioactive compound from Luffa acutangula against NF-кB-A molecular docking and dynamics approach. Computational Biology and Chemistry, 62, 29-35.

31. Golbraikh, A., Shen, M., Xiao, Z., Xiao, Y. D., Lee, K. H., \& Tropsha, A. (2003). Rational selection of training and test sets for the development of validated QSAR models. Journal of Computer-Aided Molecular Design, 17, 241-253.

32. Dixon, S. L., Smondyrev, A. M., \& Rao, S. N. (2006). PHASE: a novel approach to pharmacophore modeling and 3D database searching. Chemical Biology \& Drug Design, 67, 370-372.

33. Bharatham, K., Bharatham, N., \& Lee, K. W. (2007). Pharmacophore modeling for protein tyrosine phosphatase 1B inhibitors. Archives of Pharmacal Research, s30, 533-542.

34. Rajamanikandan, S., \& Srinivasan, P. (2016). Pharmacophore modeling and structure-based virtual screening to identify potent inhibitors targeting LuxP of Vibrio harveyi. Journal of Receptor and Signal Transduction Research, 6, 1-16.

35. Mysinger, M. M., Carchia, M., Irwin, J. J., \& Shoichet, B. K. (2012). Directory of useful decoys, enhanced (DUD-E): better ligands and decoys for better benchmarking. Journal of Medicinal Chemistry, 55, 6582-6594.

36. Truchon, J. F., \& Bayly, C. I. (2007). Evaluating virtual screening methods: good and bad metrics for the "early recognition" problem. Journal of Chemical Information and Modeling, 47, 488-508.

37. Tikhonova, I. G., Sum, C. S., Neumann, S., Engel, S., Raaka, B. M., Costanzi, S., \& Gershengorn, M. C. (2008). Discovery of novel agonists and antagonists of the free fatty acid receptor 1 (FFAR1) using virtual screening. Journal of Medicinal Chemistry, 51, 625-633.

38. Muralidharan, A. R., Selvaraj, C., Singh, S., Nelson Jesudasan, C. A., Geraldine, P., \& Thomas, P. (2014). Virtual screening based on pharmacophoric features of known calpain inhibitors to identify potent inhibitors of calpain. Medicinal Chemistry Research, $23,2445-2455$. 
39. Nair, S. B., Fayaz, S. M., \& Krishnamurthy, R. G. (2012). In silico prediction of novel inhibitors of the DNA binding activity of FoxG1. Medicinal Chemistry, 8, 1155-1162.

40. Kumar, N., \& Pruthi, V. (2015). Structural elucidation and molecular docking of ferulic acid from Parthenium hysterophorus possessing COX-2 inhibition activity. 3 Biotech, 5, 541.

41. Bhadoriya, K. S., Sharma, M. C., \& Jain, S. V. (2015). Pharmacophore modeling and atom-based 3D-QSAR studies on amino derivatives of indole as potent isoprenylcysteine carboxyl methyltransferase (Icmt) inhibitors. Journal of Molecular Structure, 1081, 466-476.

42. Therese, P. J., Manvar, D., Kondepudi, S., Battu, M. B., Sriram, D., Basu, A., Yogeeswari, P., \& Kaushik-Basu, N. (2014). Multiple e-pharmacophore modeling, 3D-QSAR, and high-throughput virtual screening of hepatitis C virus NS5B polymerase inhibitors. Journal of Chemical Information and Modeling, 54, 539-552.

43. Lauria, A., Ippolito, M., Fazzari, M., Tutone, M., Di Blasi, F., Mingoia, F., \& Almerico, A. M. (2010). IKK-beta inhibitors: an analysis of drug-receptor interaction by using molecular docking and pharmacophore 3D-QSAR approaches. Journal of Molecular Graphics \& Modelling, 29, 72-81.

44. Yang, S. Y. (2010). Pharmacophore modeling and applications in drug discovery: challenges and recent advances. Drug Discovery Today, 15, 444-450.

45. Gubareva, L. V., Robinson, M. J., Bethell, R. C., \& Webster, R. G. (1997). Catalytic and framework mutations in the neuraminidase active site of influenza viruses that are resistant to 4-guanidino-Neu5Ac2en. Journal of Virology, 71, 3385-3390.

46. Dixon, S. L., Duan, J., Smith, E., Von, Bargen, C. D., Sherman, W., \& Repasky, M. P. (2016). AutoQSAR: an automated machine learning tool for best-practice quantitative structure-activity relationship modeling. Future Medicinal Chemistry, 8, 1825-1839.

47. de Souza, A. S., de Oliveira, M. T., \& Andricopulo, A. D. (2017). Development of a pharmacophore for cruzain using oxadiazoles as virtual molecular probes: quantitative structure-activity relationship studies. Journal of Computer-Aided Molecular Design, 31, 801-816.

48. Lipinski, C. A. (2004). Lead- and drug-like compounds: the ruleof-five revolution. Drug Discovery Today: Technologies, 1, $337-341$.

49. Kalani, K., Yadav, D. K., Khan, F., Srivastava, S. K., \& Suri, N. (2012). Pharmacophore, QSAR, and ADME based semi-synthesis and in vitro evaluation of ursolic acid analogs for anticancer activity. Journal of Molecular Modeling, 18, 3389-3413.

50. Gaddaguti, V., Venkateswara Rao, T., \& Prasada Rao, A. (2016). Potential mosquito repellent compounds of Ocimum species against 3N7H and 3Q8I of Anopheles gambiae. 3 Biotech, 6, 26.

51. Fein, A. (2009). ACE inhibitors worsen inflammatory pain. Medical Hypotheses, 72, 757.

52. Morsy, M. A. (2011). Protective effect of lisinopril on hepatic ischemia/reperfusion injury in rats. Indian Journal of Pharmacology, 43, 652-655. 